\title{
Sex effects on clinical features in LRRK2 G2385R carriers and non-carriers in Parkinson's disease
}

\author{
Shi-Shuang Cui ${ }^{1,2+}$, Rao Fu ${ }^{1 \dagger}$, Juan-Juan Du', Yi-Qi Lin ${ }^{1}$, Pei Huang ${ }^{1}$, Chao Gao ${ }^{1}$, Hai-Yan Zhou ${ }^{1}$ and \\ Sheng-Di Chen ${ }^{1 *}$ (D)
}

\begin{abstract}
Background: Differences of genotypes between male and female have been studied in Parkinson's disease (PD), but limited research has focused on the comparison between sexes with LRRK2 G2385 variant.

Objective: The aim of this study was to explore sex effects in the same genetic subtype and role of leucine-rich repeat kinase 2 (LRRK2) G2385R variants in the same sex in PD.

Methods: 613 PD patients were recruited from the Movement Disorders Clinic in Ruijin Hospital. We did not include healthy controls in this study. The data collected includes demographic information, disease history, scores of motor and non-motor symptoms scales, midbrain transcranial sonography and DNA. Binary logistic regression analysis was performed to evaluate the association between clinical features and sex in LRRK2 G2385R carriers and non-carriers, as well as the association between the clinical features and LRRK2 G2385R variants in male and female sex.
\end{abstract}

Results: Sex distribution is similar in LRRK2 G2385R carriers and non-carriers. In male sex, LRRK2 G2385R carriers showed lower risk in cognitive impairment compared with non-carriers $(O R=0.301, p=0.003,95 \% C l 0.135-0.668)$. In female sex, LRRK2 G2385R carriers showed lower risk in autonomic dysfunction compared with non-carrier ( $\mathrm{OR}=0.401$, $\mathrm{p}=0.040,95 \% \mathrm{Cl}$ 0.167-0.960). In LRRK2 G2385R non-carriers, female sex showed lower risk of impairment in activity of daily living $(\mathrm{OR}=0.610, p=0.021,95 \% \mathrm{Cl} 0.400-0.928)$, excessive daytime sleepiness $(\mathrm{OR}=0.555, \mathrm{p}=0.007,95 \% \mathrm{Cl}$ $0.361-0.853)$, substantia nigra hyperechogenicity $(\mathrm{OR}=0.448, \mathrm{p}=0.019,95 \% \mathrm{Cl} 0.228-0.878)$, autonomic dysfunction frequency $(\mathrm{OR}=0.626, \mathrm{p}=0.016,95 \% \mathrm{Cl} 0.428-0.917)$ and higher risk in mood disorders $(\mathrm{OR}=1.691, \mathrm{p}=0.022,95 \% \mathrm{Cl}$ 1.078-2.654) compared with male. In LRRK2 G2385R carriers, female sex showed a lower risk of autonomic dysfunction $(\mathrm{OR}=0.294, \mathrm{p}=0.024,95 \% \mathrm{Cl} 0.102-0.849)$ compared with male.

Conclusion: In contrast to male PD patients, a more benign disease course was observed in female in both LRRK2 G2385R carriers and non-carriers. However, sex differences were less notable in PD with LRRK2 G2385R variants.

Keywords: Parkinson's disease, Sex, LRRK2 G2385R, Clinical feature, Transcranial sonographic

*Correspondence: chensd@rih.com.cn

†Shi-Shuang Cui and Rao Fu were contributed equally to this work.

1 Department of Neurology \& Institute of Neurology, Ruijin Hospital

Affiliated To Shanghai Jiao Tong University School of Medicine, 197 Rui jin

Er Road, Shanghai 200025, China

Full list of author information is available at the end of the article

\section{Backgrounds}

Sex-related differences in symptomatic and epidemiological features have been studied extensively in Parkinson's diseases (PD). A higher incidence of PD among men has been reported [1] and different clinical characteristics have been reported by sex in PD. A more rapid progression, more severe motor symptoms, greater rigidity

(c) The Author(s) 2021. This article is licensed under a Creative Commons Attribution 4.0 International License, which permits use, sharing, adaptation, distribution and reproduction in any medium or format, as long as you give appropriate credit to the original author(s) and the source, provide a link to the Creative Commons licence, and indicate if changes were made. The images or other third party material in this article are included in the article's Creative Commons licence, unless indicated otherwise in a credit line to the material. If material is not included in the article's Creative Commons licence and your intended use is not permitted by statutory regulation or exceeds the permitted use, you will need to obtain permission directly from the copyright holder. To view a copy of this licence, visit http://creativeco mmons.org/licenses/by/4.0/. The Creative Commons Public Domain Dedication waiver (http://creativecommons.org/publicdomain/ zero/1.0/) applies to the data made available in this article, unless otherwise stated in a credit line to the data. 
and increased mortality have been described among males, while a more frequent tremor-dominant subtype and a higher risk of dyskinesia and fluctuation were reported among females [2-6]. Several previous studies have investigated potential sex differences in non-motor symptoms (NMS), with less consistent findings. A previous study found that male sex in PD showed a stronger positive significant association in almost all NMS with respect to the general population [7]. Some research found that women were associated with more severe mood disorder [8-10]. Other studies found no significant differences in NMS between male and female [11, 12].

Mutation of the leucine-rich repeat kinase 2 (LRRK2) gene is the most frequent genetic cause of PD, and the G2385R variant is the most common variant observed in Asian [13, 14]. This variant was observed in more than $10 \%$ of PD patients in Chinese population but is absent in Caucasian or Jewish patients [13-15]. Some research reported more frequent subtype of postural instability/gait difficulty and motor fluctuation in patients with LRRK2 G2385R variant $[15,16]$, but no major clinical differences except for the non-significant milder non-motor symptoms were found in PD patients with LRRK2 in most previous studies $[13,17,18]$.

Different sex effects have been reported in $L R R K 2$ carriers. A previous meta-analysis indicated that LRRK2associated PD lacks a sex effect [19]. A recently published study found that patients with LRRK2 G2019S variants showed less diversity in phenotypes [20]. Nonetheless limited data are available regarding sex effect related to $L R R K 2$ G2385R variants as well as effects of $L R R K 2$ $G 2385 R$ variants in terms of sex. The aim of the present cross-sectional study was to evaluate the possible sex and LRRK2 G2385R variant differences in clinical features among PD patients, sex effects with $L R R K 2$ G2385R mutations and role of $L R R K 2$ G2385R variants in women and men with PD.

\section{Results}

Of the 855 PD patients screened for eligibility, 12 were diagnosed secondary Parkinsonism and atypical Parkinsonism, 7 carried with DBS devices and 233 patients refused genetic analyses and transcranial sonographic (TCS). Finally, 613 PD patients were analyzed, including 337 (55.0\%) men and 276 (45.0\%) women. LRRK2 G2385R variant was found in 79 (12.9\%) of them. No sex distribution differences were found between $L R R K 2$ G2385R carriers and non-carriers $(\mathrm{p}=0.729)$. The demographic and clinical features of PD patients were shown in Table 1.

\section{LRRK2 G2385R effects within the same sex}

We stratified the enrolled PD patients by sex and used binary logistic regression to analyze the association between LRRK2 G2385R carriers and non-carriers in female and male sex respectively. After adjusting age, disease duration and schooling year, we found that males with LRRK2 G2385R carriers showed lower risk

Table 1 demographic and clinical feature of female and male PD within the same genetic group

\begin{tabular}{|c|c|c|c|c|c|c|}
\hline & \multicolumn{3}{|c|}{ LRRK2 G2385R carriers $(N=79)$} & \multicolumn{3}{|c|}{ LRRK2 G2385R non-carriers $(N=534)$} \\
\hline & Female $(\mathrm{N}=37)$ & Male $(\mathrm{N}=42)$ & $P$ & Female $(\mathrm{N}=239)$ & Male $(N=295)$ & $P$ \\
\hline Age & $61.3(11.6)$ & $64.7(7.5)$ & 0.497 & $61.5(10.9)$ & $61.5(10.3)$ & 0.990 \\
\hline Disease duration & $5.2(3.1)$ & $5.4(4.1)$ & 0.807 & $5.0(4.1)$ & $5.1(4.5)$ & 0.858 \\
\hline $\mathrm{AAO}$ & $57.4(11.8)$ & $59.6(8.1)$ & 0.342 & $56.1(11.2)$ & $56.0(10.5)$ & 0.900 \\
\hline $\mathrm{H}-\mathrm{Y}$ stage & $1.7(0.5)$ & $1.8(0.6)$ & 0.565 & $1.9(0.7)$ & $1.9(0.7)$ & 0.874 \\
\hline MDS-UPDRS II & $8.8(5.5)$ & $10.7(7.1)$ & 0.189 & $8.7(7.3)$ & $9.9(7.8)$ & 0.063 \\
\hline MDS-UPDRS III & $24.7(18.7)$ & $24.6(15.9)$ & 0.968 & $22.1(17.8)$ & $25.0(19.2)$ & 0.080 \\
\hline NMSS & $24.2(30.0)$ & $30.6(32.0)$ & 0.359 & $28.7(30.7)$ & $31.0(33.3)$ & 0.414 \\
\hline MOCA & $21.7(6.9)$ & $24.7(4.2)$ & 0.046 & $22.5(5.3)$ & $23.0(4.9)$ & 0.398 \\
\hline PDSS & $96.5(49.1)$ & $109.7(44.1)$ & 0.216 & $100.7(46.0)$ & $105.8(43.0)$ & 0.186 \\
\hline HAMD & $5.1(4.6)$ & $4.3(3.9)$ & 0.384 & $5.8(5.3)$ & $5.3(5.2)$ & 0.288 \\
\hline HARS & $5.2(5.9)$ & $6.5(5.1)$ & 0.270 & $7.2(6.3)$ & $6.2(6.4)$ & 0.061 \\
\hline SS-16 & $5.8(4.0)$ & $6.8(3.8)$ & 0.270 & $6.2(4.2)$ & $5.8(3.8)$ & 0.265 \\
\hline RBD-HK & $15.2(16.4)$ & $14.1(16.5)$ & 0.753 & $13.7(16.1)$ & $14.0(18.3)$ & 0.821 \\
\hline SCOPA-AUT & $6.9(8.7)$ & $9.4(8.5)$ & 0.192 & $8.7(9.0)$ & $10.2(9.1)$ & 0.055 \\
\hline ESS & $5.1(5.5)$ & $5.8(5.9)$ & 0.574 & $4.8(5.3)$ & $6.6(6.2)$ & $<0.001$ \\
\hline PDQ-39 & $13.8(15.5)$ & 16.7 (18.5) & 0.462 & 18.0 (18.8) & $15.9(17.2)$ & 0.192 \\
\hline $\mathrm{SN}+$ & $37.5 \%$ & $38.5 \%$ & 1.000 & $28.8 \%$ & $45.3 \%$ & 0.031 \\
\hline
\end{tabular}


in cognitive impairment $(\mathrm{OR}=0.301, \mathrm{p}=0.003)$ as compared with males without LRRK2 G2385R non-carriers (Table 2) and the association remained significant after Bonferroni correction. After adjusted by age and disease duration, we found that females with LRRK2 G2385R carriers showed lower risk in autonomic dysfunction $(\mathrm{OR}=0.401, \mathrm{p}=0.040)$ as compared with females without LRRK2 G2385R non-carriers (Table 2). But the association didn't survive the Bonferroni correction.

\section{Sex effects within the same genetic subtype}

Stratified by genotypes and adjusting age and disease duration, female sex showed milder ADL impairment $(\mathrm{OR}=0.610, \mathrm{P}=0.021)$, lower risk of $\mathrm{EDS}(\mathrm{OR}=0.555$, $\mathrm{p}=0.007)$, lower risk of $\mathrm{SN}+(\mathrm{OR}=0.448, \mathrm{P}=0.019)$, lower risk of autonomic dysfunction $(\mathrm{OR}=0.626$, $\mathrm{p}=0.016)$ and higher risk of mood disorders $(\mathrm{OR}=1.691$, $\mathrm{p}=0.022)$ in non-carriers compared with male in $L R R K 2$ G2385R non-carriers (Table 3). In LRRK2 G2385R carriers, female sex showed a lower risk of autonomic dysfunction $(O R=0.294, p=0.024)$. But these associations didn't survive after Bonferroni correction.

\section{Discussion}

\section{The effect of $L R R K 2$ G2385R on clinical profile in female} and male PD

Our study indicated that sex distribution was similar between carriers and non-carriers. A previous multicenter study in China reported similar sex distribution
[13]. Consistent with a previous study, most clinical variables were similar in LRRK2 G2385R carriers and non-carriers regardless of sex [13]. However, there was two exceptions. In male sex, cognitive impairment was observed less frequent in carriers than non-carriers among PD. Similar with our study, a previous research also observed higher score of Mini-Mental State Examination (MMSE) in LRRK2 G2385R carriers than that in non-carriers in China [15]. However, other studies did not find significant differences in dementia between carriers and non-carriers $[13,21]$. The lack of association between LRRK2 G2385R variants and cognition in female may support that the effect of G2385R on cognition existed in some but not all studies. In previous studies, the frequency of autonomic symptoms was similar between $L R R K 2-\mathrm{PD}$ and idiopathic PD [13, 15, 22]. Based on the result of the current study, we also found no significant differences in autonomic dysfunction between LRRK2 G2385R carriers and non-carriers. However, in female sex, a lower risk of autonomic dysfunction was found in LRRK2 G2385R carriers compared with noncarriers. These results may indicate that the effects of $L R R K 2$ G2385R variants may different between sexes.

\section{The effect of sex on clinical profile in LRRK2 G2385R carriers and non-carriers}

In the present study, female sex in PD with $L R R K 2$ G2385R non-carriers had milder severity in motor symptoms and lower risk in EDS, autonomic dysfunction and

Table 2 the association between clinical feature and LRRK2 G2385R in male and female

\begin{tabular}{|c|c|c|c|c|c|c|c|c|}
\hline & \multicolumn{3}{|l|}{ Male } & \multicolumn{3}{|l|}{ Female } & \multicolumn{2}{|c|}{$\begin{array}{l}\text { P-value (all G2385R carriers } \\
\text { vs. all non-carriers) }\end{array}$} \\
\hline & OR $(95 \% \mathrm{Cl})$ & $p$ & Genetic power & OR $(95 \% \mathrm{Cl})$ & $\mathrm{p}$ & Genetic power & OR $(95 \% \mathrm{Cl})$ & $p$ \\
\hline EOPD & $0.430(0.174-1.061)$ & 0.067 & 0.070 & $0.870(0.355-2.130)$ & 0.760 & 0.007 & $0.595(0.316-1.120)$ & 0.108 \\
\hline Advanced stage $^{\text {a }}$ & $0.487(0.165-1.443)$ & 0.194 & 0.247 & $0.360(0.102-1.273)$ & 0.113 & 0.177 & $0.425(0.189-0.957)$ & 0.039 \\
\hline Impaired ADL ${ }^{a}$ & $1.195(0.557-2.563)$ & 0.647 & 0.074 & $1.228(0.524-2.877)$ & 0.637 & 0.078 & $1.167(0.665-2.048)$ & 0.591 \\
\hline Motor dysfunction ${ }^{a}$ & $1.540(0.746-3.177)$ & 0.243 & 0.247 & 1.647 (0.739- 3.670) & 0.166 & 0.249 & $1.549(0.908-2.642)$ & 0.108 \\
\hline Motor complication ${ }^{a}$ & $1.779(0.688-4.600)$ & 0.234 & 0.391 & $1.372(0.461-4.088)$ & 0.570 & 0.132 & $1.557(0.763-3.180)$ & 0.224 \\
\hline Cognitive impairment ${ }^{b}$ & $0.301(0.135-0.668)$ & 0.003 & 0.005 & $0.709(0.276-1.820)$ & 0.475 & 0.058 & $0.448(0.248-0.809)$ & 0.008 \\
\hline Sleep disorder ${ }^{c}$ & $0.857(0.312-2.357)$ & 0.765 & 0.077 & $1.026(0.385-2.739)$ & 0.959 & 0.048 & $1.084(1.034-1.136)$ & 0.001 \\
\hline Mood disorder ${ }^{c}$ & $0.781(0.305-1.996)$ & 0.605 & 0.119 & $0.425(0.140-1.284)$ & 0.129 & 0.169 & $0.587(0.288-1.198)$ & 0.143 \\
\hline olfaction $^{c}$ & $0.605(0.291-1.255)$ & 0.177 & 0.141 & $1.680(0.702-4.020)$ & 0.244 & 0.299 & $0.976(0.562-1.695)$ & 0.931 \\
\hline $\mathrm{RBD}^{\mathrm{c}}$ & $0.806(0.386-1.685)$ & 0.567 & 0.102 & $1.123(0.500-2.520)$ & 0.779 & 0.062 & $0.926(0.539-1.592)$ & 0.781 \\
\hline Autonomic dysfunction $^{c}$ & $0.879(0.439-1.762)$ & 0.717 & 0.070 & $0.401(0.167-0.960)$ & 0.040 & 0.044 & $0.653(0.387-1.102)$ & 0.110 \\
\hline $\mathrm{EDS}^{\mathrm{C}}$ & $0.804(0.379-2.095)$ & 0.571 & 0.103 & $1.637(0.695-3.854)$ & 0.259 & 1.637 & $1.070(0.611-1.875)$ & 0.813 \\
\hline Life quality $^{c}$ & $1.050(0.526-2.095)$ & 0.891 & 0.048 & $0.953(0.437-2.080)$ & 0.903 & 0.953 & $1.001(0.597-1.678)$ & 0.998 \\
\hline $\mathrm{SN}+{ }^{\mathrm{C}}$ & $0.773(0.236-2.530)$ & 0.670 & 0.125 & $1.602(0.344-7.455)$ & 0.548 & 1.602 & $0.988(0.388-2.519)$ & 0.980 \\
\hline
\end{tabular}

\footnotetext{
adjusted for age, disease duration and LEDD

${ }^{b}$ Adjusted for age, disease duration and years of education

c Adjusted for age and disease duration
} 
Table 3 the association between clinical feature and sex in LRRK2 G2385R carriers and non-carriers

\begin{tabular}{|c|c|c|c|c|c|c|}
\hline & \multicolumn{2}{|l|}{ LRRK2 G2385R carriers } & \multicolumn{2}{|c|}{ LRRK2 G2385R non-carriers } & \multicolumn{2}{|c|}{$\begin{array}{l}\text { P-value (all female PD vs. all male } \\
\text { PD) }\end{array}$} \\
\hline & $\mathrm{OR}(95 \% \mathrm{Cl})$ & $p$ & OR $(95 \% \mathrm{Cl})$ & $p$ & OR $(95 \% \mathrm{Cl})$ & $\mathrm{p}$ \\
\hline EOPD & $1.701(0.508-5.693)$ & 0.388 & $0.841(0.563-1.256)$ & 0.397 & $0.904(0.618-1.321)$ & 0.602 \\
\hline Advanced stage ${ }^{a}$ & $1.589(0.222-11.353)$ & 0.644 & $1.361(0.824-2.248)$ & 0.229 & $1.35(0.838-2.184)$ & 0.216 \\
\hline Impaired ADL ${ }^{a}$ & $0.599(0.183-1.957)$ & 0.392 & $0.610(0.400-0.928)$ & 0.021 & $0.617(0.416-0.913)$ & 0.016 \\
\hline Motor dysfunction ${ }^{a}$ & $0.750(0.261-2.153)$ & 0.592 & $0.695(0.473-1.019)$ & 0.063 & $0.698(0.488-0.999)$ & 0.049 \\
\hline Motor complication ${ }^{\text {a }}$ & $0.840(0.201-3.513)$ & 0.812 & $1.259(0.720-2.199)$ & 0.419 & $1.193(0.714-1.995)$ & 0.500 \\
\hline Cognitive impairment ${ }^{b}$ & $1.583(0.458-5.477)$ & 0.468 & $0.749(0.485-1.156)$ & 0.192 & $0.844(0.564-1.264)$ & 0.411 \\
\hline Sleep disorder ${ }^{c}$ & $2.006(0.525-7.655)$ & 0.309 & $1.358(0.830-2.222)$ & 0.223 & $1.417(0.893-2.247)$ & 0.139 \\
\hline Mood disorder ${ }^{c}$ & $0.854(0.211-3.459)$ & 0.825 & $1.691(1.078-2.654)$ & 0.022 & $1.594(1.041-2.441)$ & 0.032 \\
\hline olfaction $^{c}$ & $1.850(0.618-5.537)$ & 0.271 & $0.686(0.463-1.016)$ & 0.060 & $0.774(0.536-1.116)$ & 0.170 \\
\hline $\mathrm{RBD}^{\mathrm{c}}$ & $1.558(0.575-4.218)$ & 0.383 & $1.224(0.823-1.821)$ & 0.317 & $1.278(0.885-1.844)$ & 0.190 \\
\hline Autonomic dysfunction ${ }^{c}$ & $0.294(0.102-0.849)$ & 0.024 & $0.626(0.428-0.917)$ & 0.016 & $0.574(0.402-0.820)$ & 0.002 \\
\hline $\operatorname{EDS}^{\mathrm{C}}$ & $1.095(0.383-3.125)$ & 0.866 & $0.555(0.361-0.853)$ & 0.007 & 0.619 (0.417-0.919) & 0.017 \\
\hline Life quality ${ }^{c}$ & $1.024(0.394-2.644)$ & 0.961 & $1.054(0.722-1.537)$ & 0.786 & $1.003(0.986-1.019)$ & 0.764 \\
\hline $\mathrm{SN}+{ }^{\mathrm{c}}$ & $0.980(0.149-6.443)$ & 0.983 & $0.448(0.228-0.878)$ & 0.019 & $0.488(0.260-0.919)$ & 0.026 \\
\hline
\end{tabular}

a Adjusted for age, disease duration and LEDD

b Adjusted for age, disease duration and years of education

c Adjusted for age and disease duration

SN hyperechogenicity but higher risk in mood disorders, which is in agreement with most published data $[3,10$, 23-25]. Sex differences in cognition was inconsistent. Some studies found male sex were at risk, but others found female sex $[3,8,26,27]$. We also found that male sex among LRRK2 G2385R non-carriers had a tendency to develop cognitive impairment. Besides, EDS, the risk factor for cognitive impairment, was observed more frequent in male sex. It may help explain the higher susceptibility of cognitive impairment in male sex. Previous studies discovered significant positive correlations between the frequency of $\mathrm{SN}+$ and clinical scores $[24,28,29]$. Consequently, the relatively reserved motor function in female sex may be explained by the similar trends of TCS in our study. Except TCS, the similar trends were also observed by other neuroimaging and fluid biomarker, such as declined brain dopamine binding and lower urate concentrations in male patients [30, 31]. Genetics such as estrogen-related gene or brain-derived neurotrophic factor gene, hormonal influences such as estrogens, immunological factors, environmental exposures, or a combination of these are likely contributors to sex differences in PD via their influence on mitochondrial function, oxidative stress and inflammation [32-36].

However, except for the autonomic dysfunction, we didn't see any sex effects in PD with LRRK2 G2385R carriers, and the mechanism of which is still unclear. One potential explanation is that LRRK2 G2385R carriers may have a less heterogeneous phenotypic presentation than non-carriers, and this might mitigate potential sex differences due to $L R R K 2$ G2385R variants thus leading to a general tendency to neurodegeneration, which is not influenced by sex $[19,20]$.

\section{Strength and limitation}

To our best knowledge, this is the first study to study the sex effects on clinical features with and without $L R R K 2$ G2385R mutation and the role of LRRK2 G2385R on clinical features in terms of sex. Assessments in this study were comprehensive, including motor symptoms, various NMS scales and neuroimaging. Besides, we found that sex behaves differently in different genetic subtype. Further studies in LRRK2 and sex should consider stratification in design or analysis.

Limitations should be considered in interpreting our findings. We enrolled 613 individuals and only 79 was detected with LRRK2 G2385R mutation. The number of $L R R K 2$ G2385R carriers was relatively small. In addition, we only detect $L R R K 2$ G2385R, and thus non-carrier might include individual with other genetic mutation. Effects of other SNPs and genes cannot be excluded in our study. Besides, for the convenience of analysis and limitation of data, some continuous variables are being treated as binary outcomes with arbitrary cut-offs, leading to weakened powerfulness. These results became insignificant after Bonferroni correction except lower risk of LRRK2 carriers in cognitive impairment in male patients. The relatively small sample size may account for 
the insignificance after correction. Thus, a larger sample size is needed in future study. Meanwhile, the genetic power of some results was less than 0.05 , indicating, to some extent, a limited accuracy due to the relatively small sample size. Consequently, further study with large sample size and healthy subjects as controls are needed.

\section{Conclusion}

In conclusion, our findings suggested that sex distribution was similar in LRRK2 G2385R carriers and noncarriers. A more benign disease course was observed in female sex compared to male sex in both LRRK2 G2385R non-carriers and carriers. However, sex differences were less notable in PD with $L R R K 2$ variants.

\section{Methods \\ Participants}

855 PD participants in our study were enrolled between Dec 1, 2015, and Jun 30, 2018 from Movement Disorders Clinic at the Department of Neurology, Ruijin Hospital affiliated to Shanghai Jiao Tong University School of Medicine. All patients were diagnosed with PD by movement disorders specialists, according to the criteria of Movement Disorder of Society [37]. Exclusion criteria included deep brain stimulation, secondary Parkinsonism and atypical Parkinsonism, other movement disorders other than PD, severe hearing or visual loss, inability to speak or write, or other conditions that might interfere with the reliable completion of clinical assessments and patients refused to genetic analysis and TCS. The study was approved by the medical ethics committee of Rui Jin Hospital affiliated to Shanghai Jiao Tong University School of Medicine. Participants gave written informed consent before inclusion in the study.

\section{Assessments}

Demographic including age, sex and years of education were recorded during a clinical interview. Disease-related variables including age at onset (AAO) and disease duration were collected. Disease stage was assessed with the Hoehn \&Yahr staging (H-Y stage). Advanced stage was defined as more than or equal to 2.5. Disease-related decline in activity of daily living (ADL) and motor function were assessed with the Movement Disorder Society Unified Parkinson's Disease Rating Scale (MDS-UPDRS) part 2 and 3 and dichotomized on the sample median. Motor complications of therapy were assessed with MDS-UPDRS part 4. Life quality was assessed by the 39-item Parkinson disease questionnaire (PDQ-39) and dichotomized on the sample median. The equivalent daily dose of L-dopa (mg/day) (LEDD) of dopamine agonists, Catechol-O-methyltransferase (COMT) and
Monoamine oxidase (MAO-B) inhibitors was calculated for each patient as previously proposed [38].

Cognitive function was assessed with the Montreal Cognitive Assessment (MoCA) Beijing Version [39]. cutoff value for cognitive impairment was $25 / 26$ and 1-point correction for persons educated no more than 12 years. Depression and anxiety were quantified with the 17 -item Hamilton Depression Rating Scale (HAMD) and Hamilton Anxiety Rating Scale (HARS), respectively. Patients with mood disorders was defined with a cut-off of 13/14 in HAMD or 12/13 HARS [40]. Olfactory function was assessed with 16-item odor identification test from the extended version of sniffin' sticks (SS-16) and hyposmia was considered when SS-16<8.3 [41]. Autonomic function was assessed with the scale for outcomes in PD for autonomic symptoms (SCOPA-AUT) and dichotomized on the sample median. Sleep quality was assessed by the Parkinson disease sleep scale (PDSS). Poor sleep quality was defined with a cut of 82/83 in PDSS [42]. Rapid eye movement behavior disorder (RBD), and excessive daytime sleepiness (EDS) were assessed with the RBD Questionnaire-Hong Kong (RBD-HK) and Epworth Sleepiness Scale (ESS). RBD was defined that the score of RBD-HK was more than 17 [43] and EDS was defined that the score of ESS was more than 9 [44].

The TCS examinations were performed within one month after the clinical examination. An experienced sonographer who was blinded to the clinical findings of the subjects performed the examination. Through the acoustic bone window, the sonographer detected the echogenicity of the substantia nigra (SN) using a $2.5 \mathrm{MHz}$ sonographic device (MyLab90, ESAOTE, Italy) with a depth of $16 \mathrm{~cm}$ and a dynamic range of $45 \mathrm{~dB}$. The $\mathrm{SN}$ was scanned through both temporal bone windows in the axial plane. Some subjects showed no identifiable or vague midbrain structures that were insufficient to be quantitatively assessed, and these were excluded from further assessment. After identifying the butterfly shaped hypoechogenic midbrain, which was surrounded by the hyperechogenic basal cistern, the clearest image of the hyperechogenic signals in the SN region was stored. Both sides of $\mathrm{SN}$ echogenic areas from stored images were then manually encircled and measured. $\mathrm{SN}+$ was defined as the larger SN echogenic areas $(\mathrm{SNL}) \geq 18 \mathrm{~mm}^{2}$ [24].

\section{Genetic analysis}

Peripheral blood samples were collected from all 613 participants, and DNA was extracted from leukocytes using the sodium dodecyl sulfate-proteinase $\mathrm{K}$ phenol-chloro-form method. The Primer Premier 5 (version 5.00, PREMIER Biosoft International) was used to design primers for LRRK2 G2385R. Polymerase chain reaction (PCR) was performed under the following 
cycle conditions: denaturation at $94^{\circ} \mathrm{C}$ for $1 \mathrm{~min} ; 35$ cycles of denaturation at $94^{\circ} \mathrm{C}$ for $30 \mathrm{~s}$, annealing at $60^{\circ} \mathrm{C}$ for $30 \mathrm{~s}$, and elongation at $72^{\circ} \mathrm{C}$ for $30 \mathrm{~s}$ each; and a final elongation step of $1 \mathrm{~min}$ at $72^{\circ} \mathrm{C}$. After restriction enzyme digestion, the digestion products were separated by polyacrylamide gel electrophoresis $(T=6 \%$, $\mathrm{C}=5 \%$ ). The gel was dyed with 109 Genefinder (Bio-V, Xiamen, China), and the PCR products were visualized under ultraviolet light. Direct DNA sequencing of the PCR product fragments was performed using the 3070xl automated DNA analyzer (Applied Biosystems, Foster City, CA, USA).

\section{Statistical analysis}

Statistical analyses were performed with SPSS Statistics (version 20.0, SPSS Inc., Chicago, IL, USA). Continuous variables were given as means and standard deviation. Categorical variables were summarized by percentages. Chi square test was performed to test distribution differences between sex and LRRK2 G2385R variant. In order to explore the degree to which sex differences were related to gene effects, two stratified analyses were performed. To determine the sex differences within genetic groups, binary logistic analysis was performed to evaluate the possible association between sex stratified by $L R R K 2$ $G 2385 R$ variants. To assess $G 2385 R$ effects within male or female sex, binary logistic analysis was performed between $G 2385 R$ carriers and non-carriers stratified by sex. Disease stage, ADL, motor dysfunction and motor complication were adjusted for age, disease duration and LEDD. The remaining variables were adjusted for age and disease duration except that cognition adjusted for age, disease duration and schooling year. Odds Ratio (OR), 95\% Confidence Interval (CI), and p-value (two-tailed test) were computed. Significance of differences was defined as two-tailed $\mathrm{p}<0.05$. Due to multiple comparisons of logistic regression, the $P$ value was corrected with Bonferroni correction to reduce the false positive. The genetic power was calculated by Power and Sample Size Calculations (Version 3.1.2) [45, 46].

\footnotetext{
Abbreviations

AAO: Age at onset; ADL: Activity of daily living; Cl: Confidence interval; EDS: Excessive daytime sleepiness; ESS: Epworth Sleepiness Scale; HAMD: 17-Item Hamilton Depression Rating Scale; HARS: Hamilton Anxiety Rating Scale; $\mathrm{H}-\mathrm{Y}$ stage: Hoehn \&Yahr staging; LRRK2: Leucine-rich repeat kinase 2; MDS-UPDRS: The Movement Disorder Society Unified Parkinson's Disease Rating Scale; MMSE: Mini-mental State Examination; MoCA: Montreal Cognitive Assessment; NMS: Non-motor symptoms; OR: Odds ratio; PCR: Polymerase chain reaction; PD: Parkinson's diseases; PDQ-39: 39-Item Parkinson disease questionnaire; PDSS: Parkinson's disease sleep scale; RBD: Rapid eye movement sleep behavior disorder; RBD-HK: Rapid Eye Movement sleep behavior disorder questionnaire-Hong Kong; SCOPA-AUT: Scale for outcomes in Parkinson's disease for autonomic symptoms; SD: Standard deviation; SN: Substantia nigra; SS-16: 16-Item odor identification test; TCS: Transcranial sonographic.
}

Acknowledgements

We are grateful to all the patients who participated in this study and Hailun Cui for editing English-writing.

\section{Authors' contributions}

CSS did genetic analysis, performed the statistical analysis and drafted the manuscript. FR collected the information and revised the manuscript. DJJ, LYQ, HP and GC collected information of Parkinson's disease and did genetic analysis. ZHY designed this study and revised the manuscript. SDC designed this study, double-checked the statistical analysis and revised the manuscript. All authors read and approved the final manuscript.

\section{Funding}

This work was supported by Grants from the National Natural Science Foundation of China [Grant Numbers 81430022, 81771374, 91332107, 81371407], Foundation of Shanghai Municipal Education Commission (2017NKX001) and grants from Shanghai Sailing Program (19YF1429900).

\section{Availability of data and materials}

All data generated or analysed during this study are included in this published article.

\section{Declarations}

\section{Ethics approval and consent to participate}

Participants were fully informed and signed consent form before the study. The study was approved by the medical ethics committee of Ruijin Hospital affiliated to Shanghai Jiao Tong University School of Medicine.

\section{Consent for publication}

Not applicable.

\section{Competing interests}

The authors declare that the research was conducted in the absence of any commercial or financial relationships that could be construed as a potential conflict of interest.

\section{Author details}

${ }_{1}^{1}$ Department of Neurology \& Institute of Neurology, Ruijin Hospital Affiliated To Shanghai Jiao Tong University School of Medicine, 197 Rui jin Er Road, Shanghai 200025, China. ${ }^{2}$ Department of Geriatrics, Ruijin Hospital Affiliated To Shanghai Jiao Tong University School of Medicine, Shanghai 200025, China.

Received: 10 September 2020 Accepted: 7 March 2021

Published online: 26 March 2021

References

1. de Lau LML, Breteler MMB. Epidemiology of Parkinson's disease. Lancet Neurol. 2006;5(6):525-35.

2. Haaxma CA, Bloem BR, Borm GF, Oyen WJ, Leenders KL, Eshuis S, Booij J, Dluzen DE, Horstink MW. Gender differences in Parkinson's disease. J Neurol Neurosurg Psychiatry. 2007;78(8):819-24.

3. Szewczyk-Krolikowski K, Tomlinson P, Nithi K, Wade-Martins R, Talbot K, Ben-Shlomo Y, Hu MTM. The influence of age and gender on motor and non-motor features of early Parkinson's disease: Initial findings from the Oxford Parkinson Disease Center (OPDC) discovery cohort. Parkinsonism Relat Disord. 2014;20(1):99-105.

4. Baba Y, Putzke JD, Whaley NR, Wszolek ZK, Uitti RJ. Gender and the Parkinson's disease phenotype. J Neurol. 2005;252(10):1201-5.

5. Fedeli U, Schievano E. Increase in Parkinson's disease-related mortality among males in Northern Italy. Parkinsonism Relat Disord. 2017:40:47-50.

6. Zappia M, Annesi G, Nicoletti G, Arabia G, Annesi F, Messina D, Pugliese P, Spadafora P, Tarantino P, Carrideo S, Civitelli D. Sex differences in clinical and genetic determinants of levodopa peak-dose dyskinesias in Parkinson disease- an exploratory study. Arch Neurol. 2005;62:601-5.

7. Nicoletti A, Vasta R, Mostile G, Nicoletti G, Arabia G, lliceto G, Lamberti P, Marconi R, Morgante L, Barone P, et al. Gender effect on non-motor 
symptoms in Parkinson's disease: are men more at risk? Parkinsonism Relat Disord. 2017;35:69-74.

8. Song Y, Gu Z, An J, Chan P. Chinese Parkinson Study G: Gender differences on motor and non-motor symptoms of de novo patients with early Parkinson's disease. Neurol Sci. 2014;35(12):1991-6.

9. D. Georgiev KH, M. Hariz, L. Forsgren, G.-M. Hariz: Gender differences in Parkinson's disease- A clinical perspective. Acta Neurol Scand 2017:1-15.

10. Kovacs M, Makkos A, Aschermann Z, Janszky J, Komoly S, Weintraut $R$, Karadi K, Kovacs N. Impact of sex on the nonmotor symptoms and the health-related quality of life in Parkinson's Disease. Parkinsons Dis. 2016;2016:7951840

11. Khedr EM, El Fetoh NA, Khalifa H, Ahmed MA, El Beh KM. Prevalence of non motor features in a cohort of Parkinson's disease patients. Clin Neurol Neurosurg. 2013;115(6):673-7.

12. Bjornara KA, Dietrichs E, Toft M. REM sleep behavior disorder in Parkinson's disease-is there a gender difference? Parkinsonism Relat Disord. 2013;19(1):120-2.

13. Wang C, Cai Y, Gu Z, Ma J, Zheng Z, Tang BS, Xu Y, Zhou Y, Feng T, Wang $T$, et al. Clinical profiles of Parkinson's disease associated with common leucine-rich repeat kinase 2 and glucocerebrosidase genetic variants in Chinese individuals. Neurobiol Aging. 2014;35(3):725.

14. Wang C, Cai Y, Zheng Z, Tang BS, Xu Y, Wang T, Ma J, Chen SD, Langston JW, Tanner CM, et al. Penetrance of LRRK2 G2385R and R1628P is modified by common PD-associated genetic variants. Parkinsonism Relat Disord. 2012;18(8):958-63.

15. Sun $Q$, Wang T, Jiang TF, Huang P, Li DH, Wang Y, Xiao Q, Liu J, Chen SD. Effect of a leucine-rich repeat kinase 2 variant on motor and nonmotor symptoms in chinese Parkinson's disease patients. Aging Dis. 2016;7(3):230-6.

16. Gao C, Pang H, Luo XG, Ren Y, Shang H, He ZY. LRRK2 G2385R variant carriers of female Parkinson's disease are more susceptible to motor fluctuation. J Neurol. 2013;260(11):2884-9.

17. Li DWGZ, Wang C, Ma J, Tang BS, Chen SD, Chan P. Non-motor symptoms in Chinese Parkinson's disease patients with and without LRRK2 G2385R and R1628P variants. J Neural Transm. 2015;122(5):661-7.

18. Cao M, Gu ZQ, Li Y, Zhang H, Dan XJ, Cen SS, Li DW, Chan P. Olfactory Dysfunction in Parkinson's disease patients with the LRRK2 G2385R Variant. Neurosci Bull. 2016;32(6):572-6.

19. Gan-Or Z, Leblond CS, Mallett V, Orr-Urtreger A, Dion PA, Rouleau GA. LRRK2 mutations in Parkinson disease; a sex effect or lack thereof? A meta-analysis. Parkinsonism Relat Disord. 2015;21 (7):778-82.

20. San Luciano M, Wang C, Ortega RA, Giladi N, Marder K, Bressman S, Saunders-Pullman R. Michael JFFLC: Sex differences in LRRK2 G2019S and idiopathic Parkinson's Disease. Ann Clin Transl Neurol. 2017;4(11):801-10.

21. Hong JH, Kim YK, Park JS, Lee JE, Oh MS, Chung EJ, Kim JY, Sung YH, Lyoo CH, Lee JH, et al. Lack of association between LRRK2 G2385R and cognitive dysfunction in Korean patients with Parkinson's disease. J Clin Neurosci. 2017;36:108-13.

22. Marras C, Alcalay RN, Caspell-Garcia C, Coffey C, Chan P, Duda JE, et al. Motor and nonmotor heterogeneity of LRRK2-related and idiopathic Parkinson's disease. Movement Disorders. 2016;31(8):1192-202.

23. Martinez-Martin P, Falup Pecurariu C, Odin P, van Hilten JJ, Antonini A, Rojo-Abuin JM, Borges V, Trenkwalder C, Aarsland D, Brooks DJ, et al. Gender-related differences in the burden of non-motor symptoms in Parkinson's disease. J Neurol. 2012;259(8):1639-47.

24. Zhou HY, Sun Q, Tan YY, Hu YY, Zhan WW, Li DH, Wang Y, Xiao Q, Liu J, Chen SD. Substantia nigra echogenicity correlated with clinical features of Parkinson's disease. Parkinsonism Relat Disord. 2016;24:28-33.

25. Cui SS, Du JJ, Fu R, Lin YQ, Huang P, He YC, Gao C, Wang HL, Chen SD. Prevalence and risk factors for depression and anxiety in Chinese patients with Parkinson disease. BMC Geriatr. 2017;17(1):270.

26. Fengler S, Roeske S, Heber I, Reetz K, Schulz JB, Riedel O, Wittchen HU, Storch A, Linse K, Baudrexel S, et al. Verbal memory declines more in female patients with Parkinson's disease: the importance of gendercorrected normative data. Psychol Med. 2016;46(11):2275-86.

27. Cereda E, Cilia R, Klersy C, Siri C, Pozzi B, Reali E, Colombo A, Zecchinelli AL, Mariani CB, Tesei S, et al. Dementia in Parkinson's disease: Is male gender a risk factor? Parkinsonism Relat Disord. 2016;26:67-72.
28. Weise D, Lorenz R, Schliesser M, Schirbel A, Reiners K, Classen J. Substantia nigra echogenicity: A structural correlate of functional impairment of the dopaminergic striatal projection in Parkinson's disease. Mov Disord. 2009;24(11):1669-75.

29. Becker G, Bogdahn U, Reichmann H, Reiners K. Degeneration of substantia nigra in chronic Parkinson's disease visualized by transcranial colorcoded real-time sonography. Neurology. 1995;45:182-4.

30. Kaasinen V, Joutsa J, Noponen T, Johansson J, Seppanen M. Effects of aging and gender on striatal and extrastriatal [1231]FP-CIT binding in Parkinson's disease. Neurobiol Aging. 2015;36(4):1757-63.

31. Schwarzschild MA, Marek K, Eberly S, Oakes D, Shoulson I, Jennings D, Seibyl J, Ascherio A. Parkinson Study Group PI: Serum urate and probability of dopaminergic deficit in early "Parkinson's disease." Mov Disord. 2011;26(10):1864-8.

32. Mitra S, Chakrabarti N, Dutta SS, Ray S, Bhattacharya P, Sinha P, Bhattacharyya A. Gender-specific brain regional variation of neurons, endogenous estrogen, neuroinflammation and glial cells during rotenone-induced mouse model of Parkinson's disease. Neuroscience. 2015;292:46-70.

33. Kedmi M, Bar-Shira A, Gurevich T, Giladi N, Orr-Urtreger A. Decreased expression of $B$ cell related genes in leukocytes of women with Parkinson's disease. Mol Neurodegener. 2011;6:66.

34. Marras C, Saunders-Pullman R. The complexities of hormonal influences and risk of Parkinson's disease. Mov Disord. 2014;29(7):845-8.

35. Foltynie T, Lewis SG, Goldberg TE, Blackwell AD, Kolachana BS, Weinberger DR, Robbins TW, Barker RA. The BDNF Val66Met polymorphism has a gender specific influence on planning ability in Parkinson's disease. J Neurol. 2005;252(7):833-8.

36. Chung SJ, Armasu SM, Biernacka JM, Lesnick TG, Rider DN, Cunningham $\mathrm{JM}$, Maraganore DM. Variants in estrogen-related genes and risk of Parkinson's disease. Mov Disord. 2011;26(7):1234-42.

37. Postuma RB, Berg D, Stern M, Poewe W, Olanow CW, Oertel W, Obeso J, Marek K, Litvan I, Lang AE, et al. MDS clinical diagnostic criteria for Parkinson's disease. Mov Disord. 2015;30(12):1591-601.

38. Tomlinson CL, Stowe R, Patel S, Rick C, Gray R, Clarke CE. Systematic review of levodopa dose equivalency reporting in Parkinson's disease. Mov Disord. 2010;25(15):2649-53.

39. Nasreddine ZSPN, Bedirian V, Charbonneau S, Whitehead V, Collin I, Cummings $\mathrm{J}$, Chertkow H. The montreal cognitive assessment, MoCA: a brief screening tool for mild cognitive impairment. J Am Geriatr Soc. 2005;53(4):696-9.

40. Martinez-Martin P, Leentjens AF, de Pedro-Cuesta J, Chaudhuri KR, Schrag AE, Weintraub D. Accuracy of screening instruments for detection of neuropsychiatric syndromes in Parkinson's disease. Mov Disord. 2016;31(3):270-9.

41. Chen WKW, Chen S, Wang Y, Xiao Q, Wang G, Liu J, Chen SD. Hyposmia correlates with SNCA variant and non-motor symptoms in Chinese patients with Parkinson's disease. Parkinsonism Relat Disord. 2015;21(6):610-4.

42. Martinez-Martin P, Visser M, Rodriguez-Blazquez C, Marinus J, Chaudhuri KR, van Hilten JJ. SCOPA-sleep and PDSS: Two scales for assessment of sleep disorder in Parkinson's disease. Mov Disord. 2008;23(12):1681-8.

43. Shen SS, Shen Y, Xiong KP, Chen J, Mao CJ, Huang JY, Li J, Han F, Liu CF. Validation study of REM sleep behavior disorder questionnaire-Hong Kong (RBDQ-HK) in east China. Sleep Med. 2014;15(8):952-8.

44. Simuni T, Caspell-Garcia C, Coffey C, Chahine LM, Lasch S, Oertel WH, Mayer G, Hogl B, Postuma R, Videnovic A, et al. Correlates of excessive daytime sleepiness in de novo Parkinson's disease: A case control study. Mov Disord. 2015;30(10):1371-81.

45. Dupont WDPW. Power and sample size calculations for studies involving linear regression. Control Clin Trials. 1998;19:589-601.

46. Dupont WDPW. Power and sample size calculations: a review and computer program. Control Clin Trials. 1990;11:116-28.

\section{Publisher's Note}

Springer Nature remains neutral with regard to jurisdictional claims in published maps and institutional affiliations. 